\title{
Anti-slip Readhesion Control with Presumed Adhesion Force - Method of Presuming Adhesion Force and Running Test Results of High-speed Shinkansen Train -
}

\author{
Tomoki WATANABE \\ Chief Engineer, Traction Control G., \\ Vehicle Technology Development Div., \\ Technological Development Dept.
}

\begin{abstract}
To analyze slip phenomena, we propose a new practical readhesion control for electric railway vehicles with three-phase drive. The keypoints are optimized axle velocity detection, detection of small slip, slight reduction of torque and torque recovery at readhesion. By running tests with a prototype Shinkansen train "STAR 21", we obtained good results. Nevertheless, slip-readhesion iteration occurs under very bad wheel-rail conditions. So we introduced wheel-rail adhesion prediction in addition and succeeded in utilizing as much adhesion force as possible under any wheel-rail condition. Especially this control has remarkable performance under very bad conditions such as icy rail, steep gradient etc.
\end{abstract}

Keywords : high-speed train, electric multiple unit, Shinkansen, adhesion, anti-slip control, readhesion, control

\section{Forward}

To solve wheel slip / slide problems of electric railway vehicles, it is very important to grasp exactly wheel slip / slide phenomena in powering / braking while trains run. And axle velocity detection is of greater importance in observing slip/slide phenomena and has more restrictions than in other applications such as elevators, mill controllers of steel industry, etc. that usually use encoders or speed sensors of much higher resolution. So we have to develop a method of velocity detection focused on the wheel slip / slide phenomena, which differs from rotational velocity detection for motor control at a few points. Information on laboratory test results is limited. Slip detection and readhesion control is needed mainly under bad wheel-rail condition. So we study readhesion control based primarily on running test results with water sprayed between wheel and rail.

At first, we optimized axle velocity detection to observe slip/slide phenomena. Then we analyzed slip phenomena of running trains. We propose small slip detec-

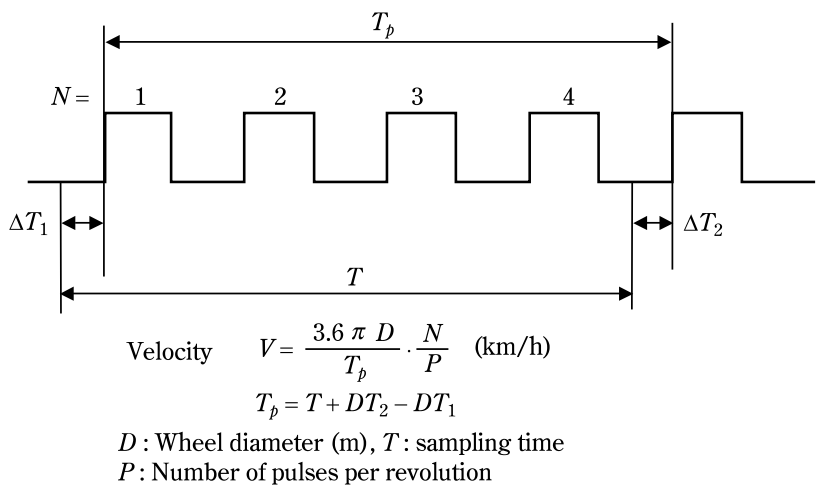

Fig. 1 Average Pulse Width Calculation tion and slight torque reduction as a practical readhesion control and we obtained good results by using STAR 21 prototype Shinkansen train. But reiteration of slip-slide occurs under very bad wheel-rail conditions. So we propose adhesion prediction at slip detection to cope with this reiteration. We obtained very good test results and succeeded in utilizing adhesion force between wheel and rail as much as possible under any wheel-rail adhesion condition.

Following is our experience.

\section{How to obtaine accurate axle velocities}

To obtaine accurate axle velocities you must be careful in choice and installation of speed sensors. First, the eccentricity between the axle on which the speed sen-

Table 1 Method of velocity / acceleration calculation for anti-slip / slide detection

\begin{tabular}{|l|l|}
\hline Velocity & $\begin{array}{l}\text { Average pulse width calculation of } \\
\text { pulses in a sampling time }\end{array}$ \\
& $\begin{array}{l}\text { Sampling time : } 100 \mathrm{~ms} \\
\text { Timer of pulse width counting : } 100 \mathrm{~Hz} \\
\text { Renewal of velocity : every } 25 \mathrm{~ms}\end{array}$ \\
\hline Acceleration & $\begin{array}{l}\text { Calculate from velocity difference } \\
\text { btw. latest one and one 100 ms before }\end{array}$ \\
\hline
\end{tabular}

Table 2 Comparison of Control of inverter and control tester (case of Fig. 9)

\begin{tabular}{|l|l|}
\hline $\begin{array}{l}\text { Controller of the inverter } \\
\text { Axles No.7, } 9,10\end{array}$ & $\begin{array}{l}\text { Control tester (our proposal) } \\
\text { Axle No.8 }\end{array}$ \\
\hline Short time velocity & Velocity detection using $100 \mathrm{~ms}$ \\
detection $(5 \mathrm{~ms}$ ) and filtering & interval, renewal every $25 \mathrm{~ms}$ \\
current reduction & current reduction in accordance \\
following fixed pattern & with slip velocity and acceleration \\
\hline
\end{tabular}




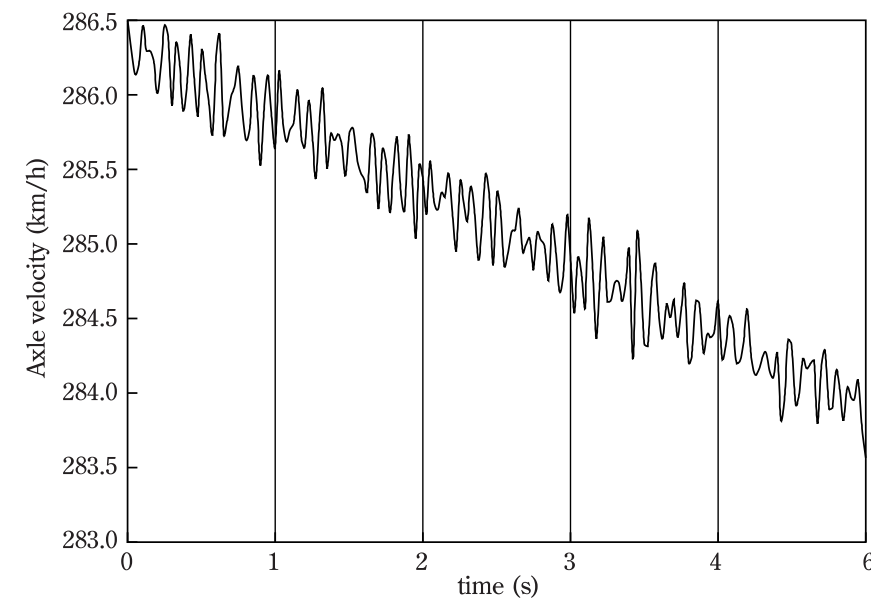

Fig. 2 An axle velocity in time of coasting (velocity calculation time $T=25 \mathrm{~ms}$ ) E'2 Shinkansen. Speed sensor is mounted in traction motor.

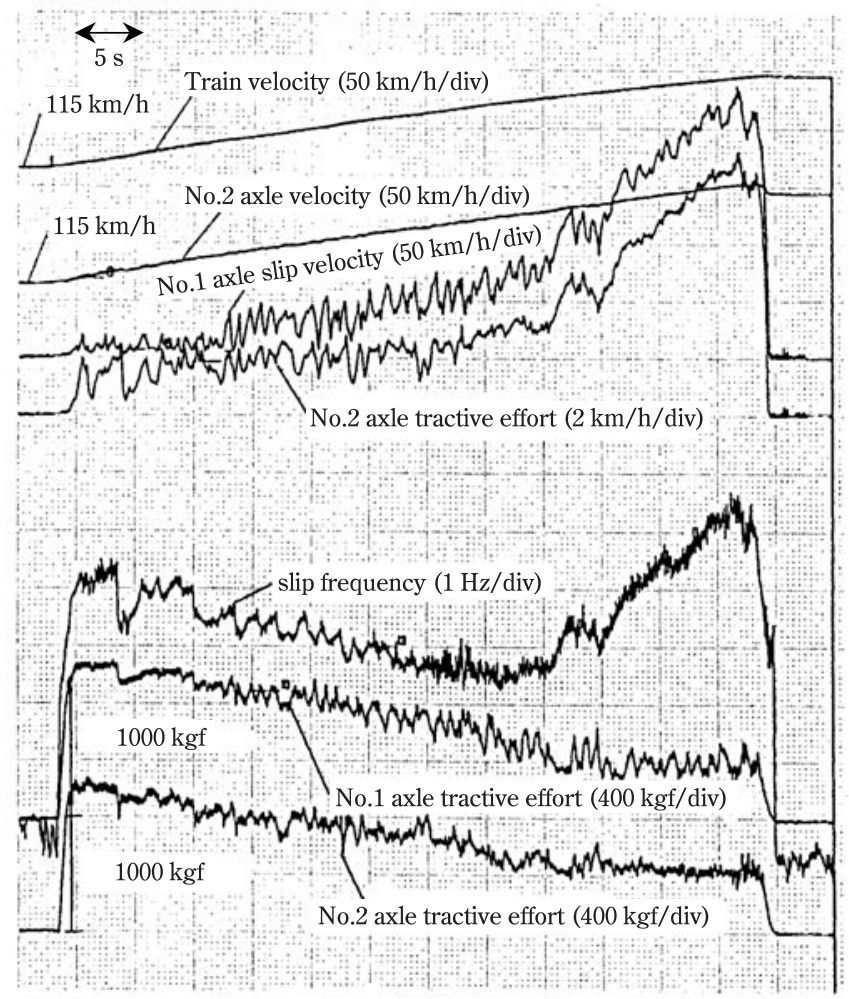

Fig. 4 A result of running tests E2' Shinkansen train

sor is mounted and the speed sensor axle must be very small because it causes an instantaneous velocity fluctuation. If you use a pin-drive speed sensor it may be a wrong choice for anti-slip / anti-slide control. The conventional way to detect train velocity is to calculate pulses of speed sensor installed at one end of the wheel axle or traction motor axle. In railway application, it is usually very difficult to realize a sensor with as many pulses per rotation as the encoder has in other industrial applications. So we have used an average pulse width calculating method (Fig. 1). We think that this method is inevitable for detection of small slips and readhesion control. From our experience we propose the

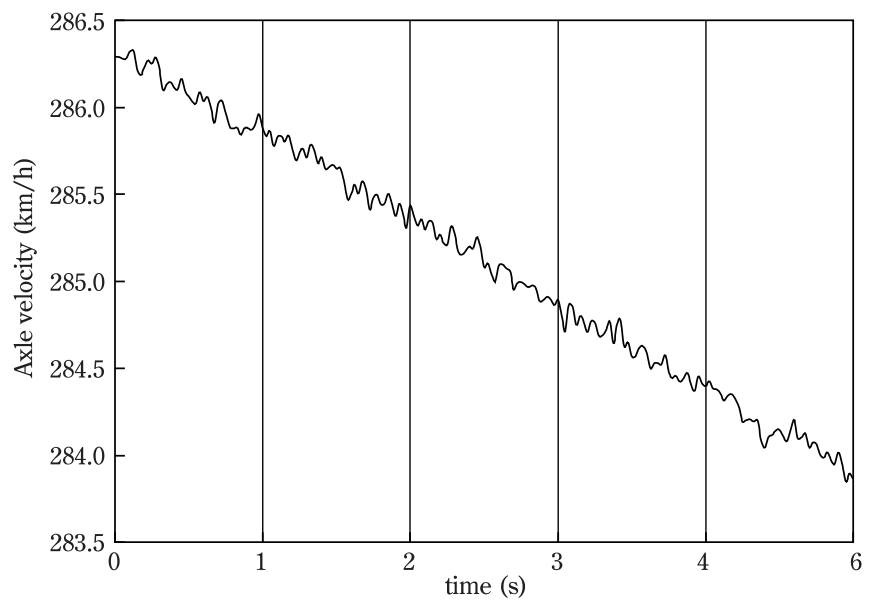

Fig. 3 An axle velocity in time of coasting (velocity calculation time T = $100 \mathrm{~ms}$ ) E2' Shinkansen. Speed sensor is mounted in traction motor.

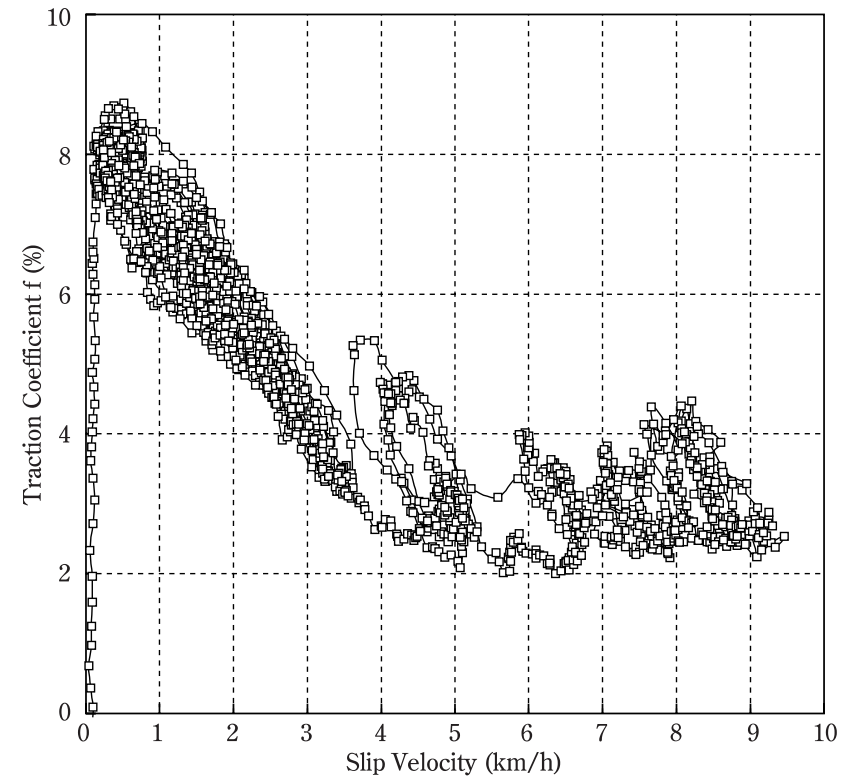

Fig. 5 An example of traction coefficient of Shinkansen train (powering, water spayed on rail)

calculation in Table 1.

Fig. 2 shows an axle velocity of E2 Shinkansen train in time of coasting at a velocity calculation time (sampling time) of 25 miliseconds. In this case, speed sensors are mounted on the traction motor. You can see about $\pm 0.3 \mathrm{~km} / \mathrm{h}$ fluctuation at about $10 \mathrm{Hertz}$. We presume that this velocity fluctuation results from the mutual movement between wheelset and traction motor mounted on the bogie. So you must use velocity calculation time longer than 100 miliseconds. Fig. 3 shows the same axle velocity at a velocity calculation time of 100 miliseconds. From these figures, it is clear that velocity calculation time must be optimized according to its purpose such as traction motor control, antislip control, train control etc.

It can be proved that errors in calculated acceleration become a minimum when time interval of acceleration equals to that of velocity calculation. 


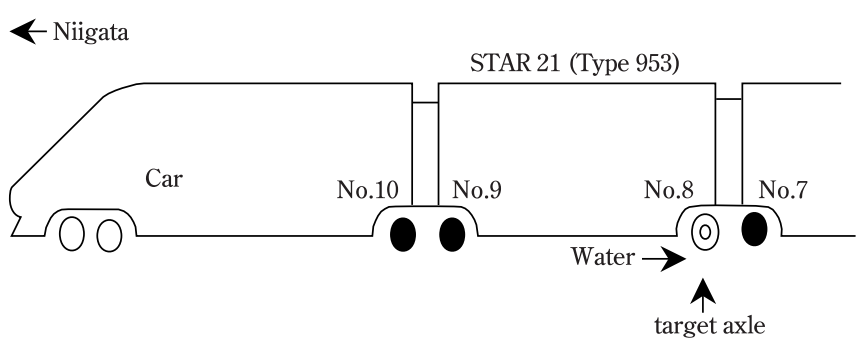

Fig. 6 Tested vehicles of STAR21 train

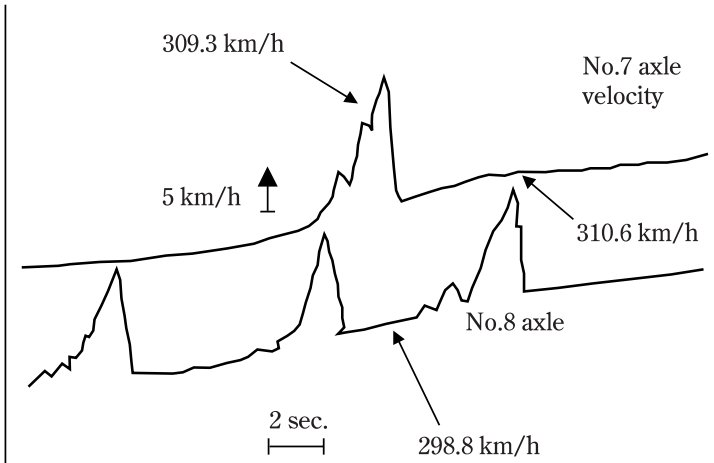

No.7 axle current

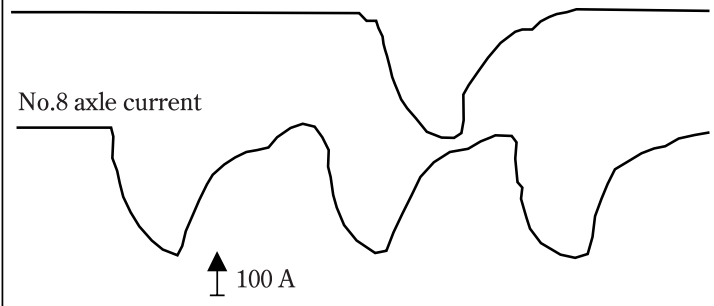

Fig. 7 Running test results of STAR21 (DEC. 8th '93)

\section{Adhesion phenomena}

Fig. 4 shows a running test result with water sprayed on rail that cause gradual increace of slip velocities. From analyzed results of this case (Fig. 5), it is clear that we can get the maximum adhesion force at the slip velocity of $0.5 \mathrm{~km} / \mathrm{h}$. Our running test experience of antislip/anti-slide control ranging from commuter trains to Shinknasen trains (both powering and mechanical braking) proves that the maximum adhesion force lies below the slip speed of $2 \mathrm{~km} / \mathrm{h}$ even in $300 \mathrm{~km} / \mathrm{h}$ train running.

\section{Readhesion control}

Slip velocity control that keeps slip velocity at the reference value is described in papers. ${ }^{9)} 10$ ) In this case, the reference slip velocity is given as a linear function of vehicle velocity and the slip velocity controller is formed by feeding back the real value of slip velocity. They state that the step response time of torque must be as quick as $5 \mathrm{~ms}$, so a field-oriented control of traction motors is needed [11]. The reference slip velocity is obtained on a real-time basis by searching an optimal slip velocity. ${ }^{11)}$ 12) 13) 14)

We intend to solve the problem more easily for all torque-controllable electric motor vehicles and propose the following method based on our running test experience.

(1) We obtain axle velocities by the above mentioned method. Here we call the minimum/ maximum value of four or more axle velocities in powering/braking a pseudo train velocity (or a reference velocity) and the difference between axle velocity and reference velocity a (pseudo) slip velocity.

(2) We detect a small pseudo slip/slide velocity by using the threshold level of less than $1 \mathrm{~km} / \mathrm{h}$, for example.

(3) Then we reduce the torque of the relevant traction motor. The current reduction takes place in steps proportional to the pseudo slip of the axle.

(4) We recover torque as soon as we detect readhesion. Our proposed readhesion control has following advantages.

(1) Detection of small slip/slide minimizes torque reduction required for readhesion.

(2) By detecting small slips and preventing large slips, we can avoid losing the train velocity. The reference velocity follows well the train velocity.

(3) This practical method of readhesion control applies to both the conventional slip frequency control and vector control. Because slip phenomena do not change so fast, we will succeed in keeping slip velocity at a small value.

(4) Almost all electric motor vehicles have an Automatic Current Regulator that substantially aggravates readhesion characteristics. We recommend such a design that control circuit does not promote slip/slide when it occurs. But it is not necessary, because the following running test was performed without changing the Automatic Current Regulator and we ob-

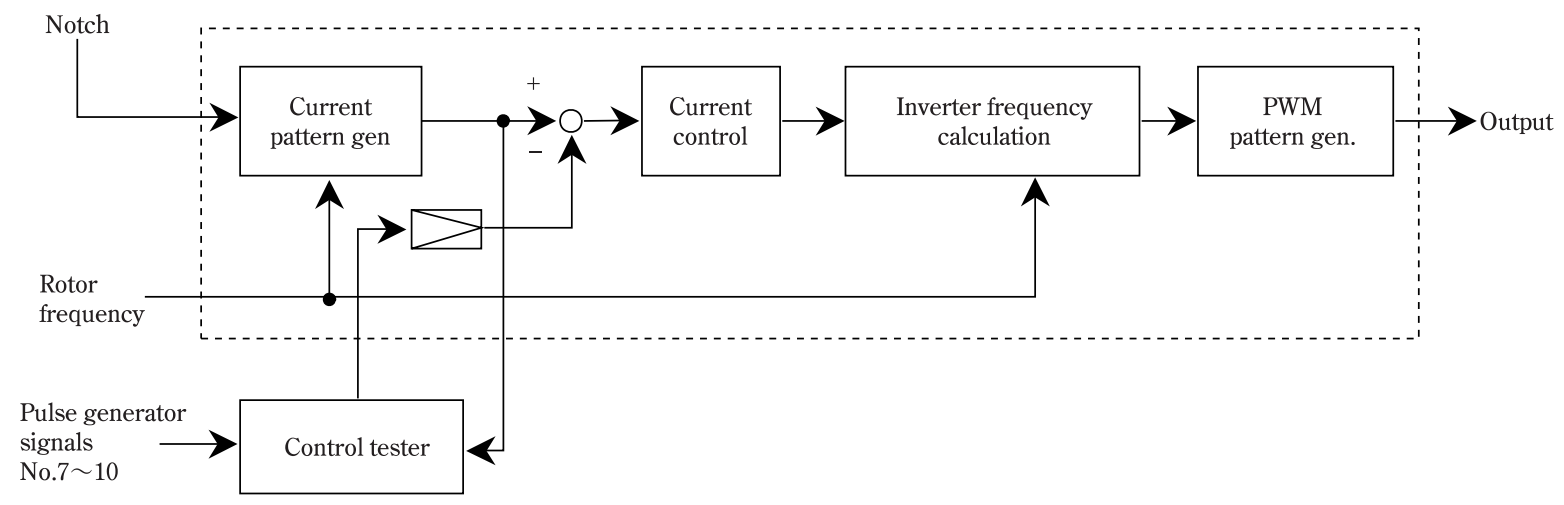

Fig. 8 Control tester and inverter control unit 


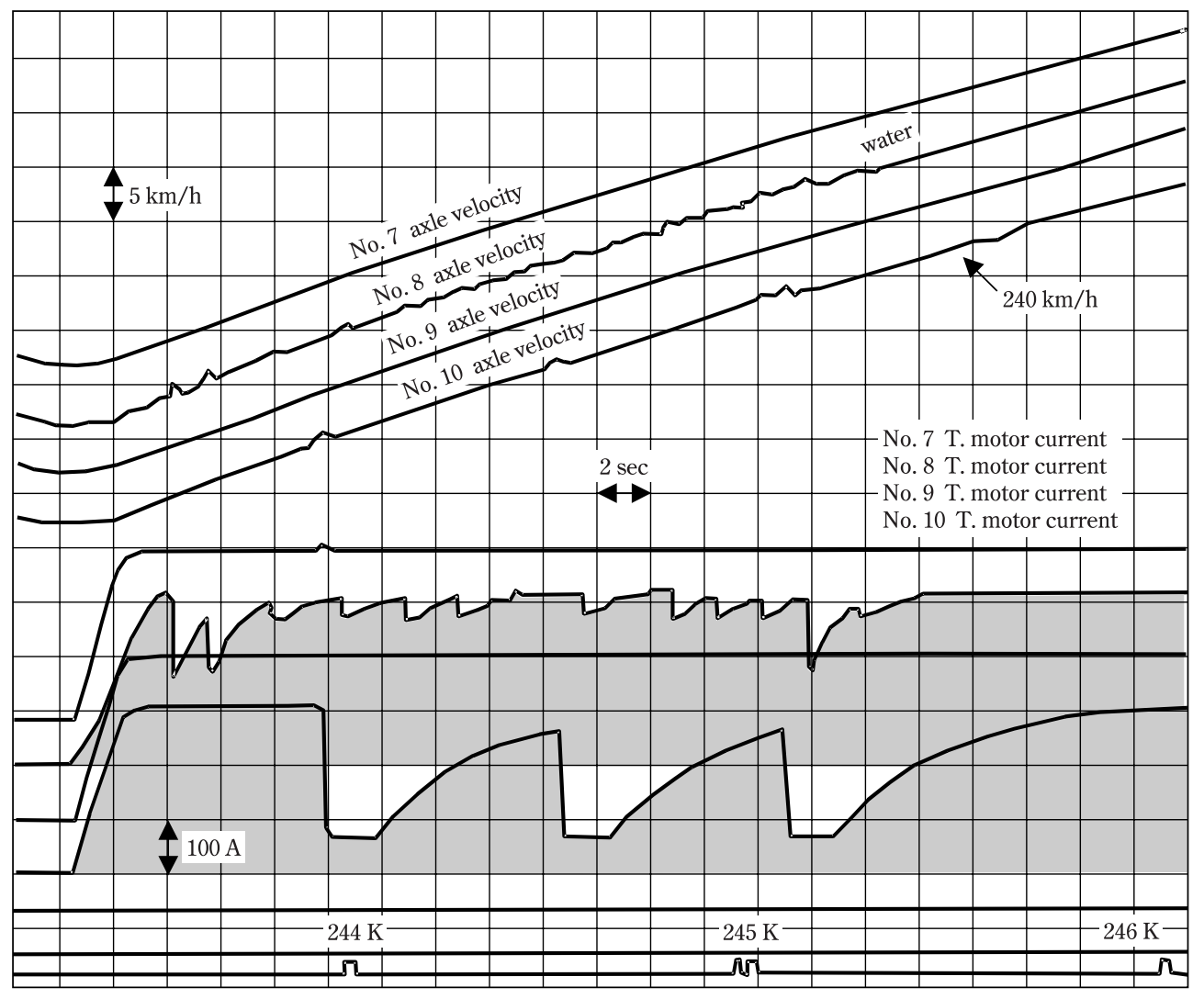

Fig. 9 First step test results of STAR21 (control applied to 8th wheel)
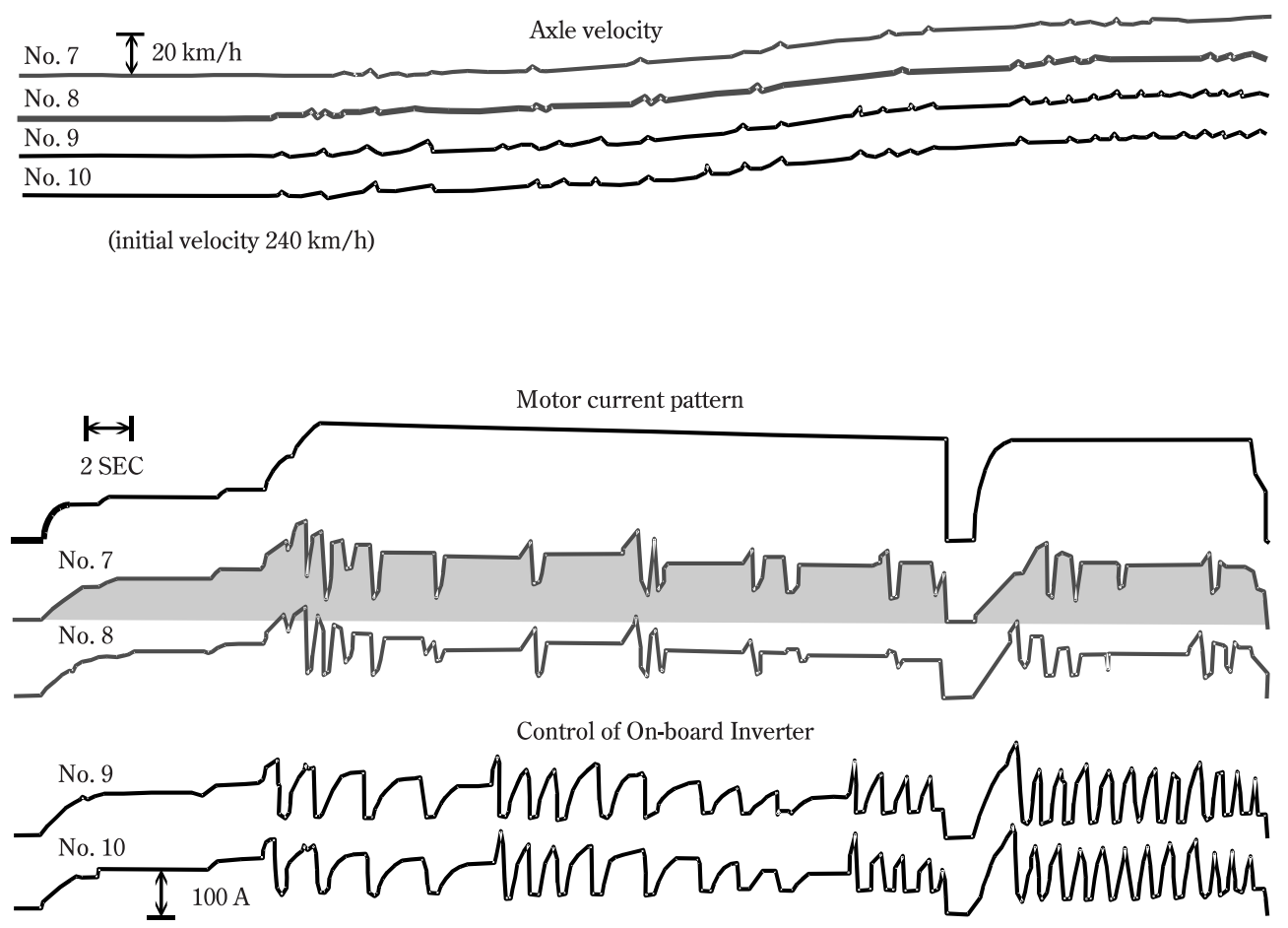

Fig. 10 Test results of STAR21 (Readhesion control with adhesion prediction applied to 7th and 8th axles)

tained good results.

5. Test results and optimization with STAR21 Shinkansen train

We performed running tests with STAR21 
Shinkansen train (Fig. 6). At the first step, we measured the axle velocities of STAR21 with water sprayed on rail. From Fig. 7, we can see relatively large slips and large traction motor current reduction.

To make on-board optimization process faster, we installed a "Control Tester" between master controller and inverter controller(Fig. 8). The control tester detects wheel slip and issues a current reducing order to the inverter controller. The control parameter can be changed directly from the keyboard of the control tester.

The axle No. 8 in Fig. 9 shows running test results of the proposed readhesion control in 1994. We succeeded in keeping both smaller slips and higher traction motor currents than by the conventional inverter controller (No. 10 axle).

However, we found that frequent repetition of slipreadhesion and large fluctuation of traction motors occur under bad wheel-rail conditions or when adhesion force is much lower than the tractive effort determined by the traction motor current.

We introduced a learning control by using adhesion prediction. The difference in force between tractive effort and adhesion force (= traction force) causes acceleration of axle. So adhesion force $f_{a}$ can be predicted by

$f_{a}=f_{t}-K * \alpha$

$f_{t}:$ Tractive effort

$K$ : Constant (rotational inertia)

$\alpha$ : Axle acceleration

Axles Nos. 7 and 8 in Fig 10 show test results of our new proposal. We succeed in stopping slip-readhesion reiteration and in keeping traction motor current much more stable.

\section{Conclusions}

As a practical method of readhesion control for electric motor vehicles with a three-phase drive, we recommended a design in which the control circuit does not spur slip by using the lowest velocity of all motor axles as a reference frequency value of inverters and feeding asynchronous traction motors. And we propose detection of a small pseudo slip, a slight reduction of traction motor current at detection and torque recovery at readhesion detection. Furthermore, we add online adhesion prediction to cope with slip-readhesion reiteration under very bad wheel-rail conditions. Running test results show the effectiveness of our proposed readhesion control.

\section{References}

1) Watanabe, T., Ogasa, M. : "Improvement of readhesive chracteristics of electric motor vehicles by Slip Velocity Feedback Torque Control”, Speedam, pp.373-378, 1992, Positano

2) Watanabe, T., Ogasa, M. : "Realization of Anti-slip/ slide Control in Railway Motor Vehicles by Slip Velocity Feedback Torque Control", EPE '93, Vol.6, pp.156-161, Aahen

3) Aburaya, K. : "Technical trend of inverter controlled electric vehicles, Denkisha no Kagaku”, Vol.43, No.2, p.15, 1990 (in Japanese)

4) Watanabe, T., Ogasa, M., Ohe, S. : "Improvement of Re-adhesive Characteristics of Electric Motor Vehicles", STECH '93, pp.243-247, Yokohama

5) Yasukawa, S., Ohe, S. : "A study on Readhesion Control for the Inverter Controlled Motor Vehicle by Simulation", National conv. rec. IEEJ-IAS, 6, 1990 (in Japanese)

6) Nakazawa, H., Kikuchi, T. : "VVVF inverter control equipment of series 05 of Tozai line of TRTA", Denkisha no Kagaku, Vol.44, No.12, pp.13-20, 1991 (in Japanese)

7) Watanabe, T. : "Precise Detection of Train Velocity", National conv. rec. IEEJ-IAS, 12, 1989 (in Japanese)

8) Watanabe, T., Komoto, Y. : "Automatic Split and Combine System of the Shinkansen train", CCCT '89 (IFAC), pp.123-129, Paris

9) Weinhardt, M. : "Erkenntnisse und Maßnahmen zur Hochausnutzung des Kraftschlusses auf modernen Triebfahrzeugen”, AET, 42, pp.119-144, 1987

10) Kok, F., Weinhardt, M. : "Tractive effort and wheel slip control of locomotive type 120", 10th World Congress on Automatic Control (IFAC), Vol.3, pp.259-267

11) Buscher, M., Pfeiffer, R., Schwarz, H-J. : "Radschlupfregelung für Drehstrom-lokomotiven", Elektrische Bahnen, Vol.91, No.5, pp.163-178, 1993

12) Vogel, U. : "Untersuchung eines Verfah-rens zur Hochausnutzung des Rad-Schiene- Kraftschlusses bei Triebfahrzeugen", Elektrische Bahnen, Vol.89, No.10, pp.285-292, 1991

13) Vogel, U. : "Auwendung eines Verfahvens zur Hochausnutzung des Rad-Schiene-Kraftschlusses auf ein Digitalrechner-modell der Lokomotive Baureihe 120", Elektrische Bahnen, Vol.90, No.12, pp.359-365, 1992

14) Köber, J. et al : "Die Weiterentwicklung der Leistungs- und Steuerungselektronik gemäß den Anforderungen des modernen Schienenverkehrs", ZEV Glases. Ann Vol. 114, No.11/12, pp.503-511, 1990

15) Kimura, A., Nakamura, K. : "Study on the Stabilization of Control Systems for Induction Moter Drived Rolling Stock”, T.IEE Japan, Vol.110-D, No.3, pp.291298, 1990 (in Japanese) 